política e a multiplicação das formas de vida aceitas e valorizadas, além da superação de barreiras - envolvendo concepções do direito e do urbanismo - até hoje preservadas entre economia e sociedade. Esta superação, exigida pelo conteúdo da coletânea, representa enorme desafio para as disciplinas inscritas no campo do planejamento territorial.

\section{APOLOGIA DA DERIVA: ESCRITOS SITUACIONISTAS SOBRE A CIDADE}

Paola Berenstein Jacques (Org.)

Rio de Janeiro: Casa da Palavra, 2003.

Thais de Bhanthumchinda Portela (UFRJ)

O supra-sumo do espetáculo é o planejamento da felicidade. Raoul Vaneigem, 1961

No período entre guerras, o campo da arquitetura e do urbanismo presenciou o fortalecimento do discurso poético - na busca de soluções dos problemas sociais - e pragmático - no uso da racionalidade técnica para a reconstrução das cidades arrasadas pela guerra propostos nos primeiros CIAMs (Congressos Internacionais de Arquitetura Moderna). Já no pós-guerra, em 1947, no retorno dos Congressos, a cada encontro passou a dominar a figura de Le Corbusier, com o discurso do funcionalismo separatista apresentado na Carta de Atenas (1933) e encaminhado por princípios racionais cartesianos.

Em um contexto de grande destruição que gerava a necessidade de rápida reconstrução dos espaços urbanos e de grandes investimentos na habitação, aliado ao fortalecimento de uma produção industrial de modelo fordista - produção estandardizada, uso de carros, trabalho na fábrica com horários para a produção e para o descanso bem determinados etc. - fizeram que os princípios da Carta de Atenas para o funcionamento da cidade - trabalhar, circular, habitar e recrear - fossem utilizados em larga escala por todo continente europeu, sendo depois transformado em um grande modelo de construção de cidades em diversos países com pretensão a se "modernizar/desenvolver".

Este modernizar as cidades mundo afora seguindo a cartilha do funcionalismo racionalista cartesiano virou cânone, tanto na Academia quanto nos escritórios de projetos, marca do que viria a ser considerado a boa arquitetura e o urbanismo de qualidade. Além disso, na medida em que acontecia a modernização das cidades o Urbanismo fortalecia-se como disciplina, ganhando espaços nos poderes públicos e privados para projetar e planejar as cidades. Aliás, cidade que se prestasse, que fosse desenvolvida, era sinônimo de cidade bem planejada. 
Assim caminhava a história e, quando o mundo deu por si, descobriu que o movimento moderno havia se transmutado em modernismos (ismos, exacerbação de um movimento), havia matado as esquinas, o encontro, a história, a poesia... De "a grande solução" dos problemas urbanos, o movimento moderno passou para a categoria de "vilão". Decretada sua morte, o mundo viu surgir uma nova safra de intelectuais, críticos ao movimento, entrando então em um mundo pós-moderno, contemporâneo, marcado pela preocupação com a história, com a política, o social e a economia local etc.

Certo? Não. Isso não passa de um senso comum, ditado por uma leitura que privilegia um determinado pensamento que, com o passar do tempo, tornouse hegemônico no campo da história do urbanismo. Talvez pelo fato de que os cânones da arquitetura e do urbanismo modernos ajudaram, e muito, o fortalecimento do campo disciplinar do urbanismo e do planejamento urbano.

Mas, o fato é que a crítica ao movimento moderno surgiu no mesmo momento histórico que o pensamento modernista. Isto é mostrado através da história e da vida de um grupo de intelectuais franceses que se denominavam Situacionistas. "Gravíssimo sinal de decomposição ideológica atual é ver a teoria funcionalista da arquitetura fundamentar-se nos conceitos mais reacionários da sociedade e da moral. Significa que, as contribuiçóes parciais passageiramente válidas da primeira Bauhaus ou da escola de Le Corbusier, acrescenta-se em surdina uma noção atrasadíssima da vida e de seu enquadramento" (Guy Debord, 1957, p.50); e também por um outro grupo inserido no próprio movimento moderno e participante ativo dos CIAMs, o Team X. E é isso que o livro organizado por Berenstein vem apresentar.

Nele, encontram-se coletados e organizados diversos textos produzidos pelo grupo dos Situacionistas. Mas afinal, quem são eles? Inspiração para grupos do movimento antiglobalização contemporâneo, como os grupo Black Blocks (aqueles tocadores de tambor que se vestem de preto e animam todos os encontros de protesto antiglobalização), do Reclaim the Streets (invasores de espaços públicos como ruas, praças etc. que, através de festas e manifestaçōes perfomáticas, reclamam o espaço público como direito dos pedestres e cidadãos), entre outros. A Internacional Situacionista foi fundada a par- tir da fusão dos grupos do Mibi (Movimento Internacional por uma Bauhaus Imaginista), do IL (Internacional Letrista) e da Associação Psicogeográfica de Londres (nome e associação inventados, durante este encontro de fundação, por Ralph Rumney), ${ }^{1}$ em 28 de julho de 1957, em um bar nos arredores de Cosio d'Arroscia.

Pelo lugar de fundação do movimento pode-se tomar por entendido a informalidade e, por conseguinte, a vontade da não-institucionalização do grupo, o que não significava falta de rígidos princípios e conceitos. Por sinal, estes vão ser um dos principais motivos dos rachas constantes entre os Situacionistas, capitaneado principalmente por um de seus fundadores e principal intelectual, Guy Debord.

Jovens agitadores, decididos a mudar o sistema através de uma revolução cultural, a International Situacionista produziu uma crítica ao urbanismo funcionalista racional, bebendo de diferentes fontes: da produção sobre a vida cotidiana de Henri Lefevbre, passando pelo grupo Cobra (constituído em 1948, em um café no Quai St. Michel, por um grupo que reclamava da superficialidade do debate do Centro Internacional para a Documentação da Arte de Vanguarda em Paris) ${ }^{2}$ ao S e B (Socialisme ou barbarie, publicação de militantes rompidos com o trotskismo que conduziu a um questionamento do marxismo, cujo principal teórico era Cornelius Castoriadis) ${ }^{3}$.

Deste caldo surgiu a revolução proposta pelos Situacionistas: arte, política e filosofia voltadas para a descoberta de possibilidades de uso do ambiente urbano, induzindo a participação transformadora do cotidiano alienado e passivo da Sociedade do Espetáculo principal teoria de Debord -, e propóe, então, o uso do urbanismo unitário: "emprego do conjunto das artes e técnicas, como meios de ação que convergem para uma composição integral do ambiente" (p.54).

O urbanismo unitário é dinâmico, isto é, tem estreita ligação com estilos de comportamento. O elemento mais reduzido do urbanismo unitário não é a casa, mas o complexo arquitetônico - reunião de todos os fatores que condicionam uma ambiência, ou uma série de ambiências contrastantes, na escala da situação construída. O desenvolvimento espacial deve levar em

1 HOME, Stuart, Assalto à cultura: utopia subversão guerrilha na (anti)arte do século XX. São Paulo: Conrad Editora do Brasil, 1999, p.52.

2 Idem, ibidem, p.23.

3 Idem, ibidem, p.68. 
conta as realidades afetivas que a cidade experimental vai determinar.

Nos textos coletados por Berenstein estão descritas as principais atividades propostas pelo grupo:

- psicogeografia: "estudo das leis exatas e dos efeitos precisos do meio geográfico, planejado conscientemente ou não, que agem diretamente sobre o comportamento afetivo dos indivíduos" (p.39);

- construção de situações: "construção de situações, isto é, a construção concreta de ambiências momentâneas da vida, e sua transformação em uma qualidade passional superior. Devemos elaborar uma intervenção ordenada sobre os fatores complexos dos dois grandes componentes que interagem continuamente: o cenário material da vida; e os comportamentos que ele provoca e que o alteram" (p.54);

- deriva: um dos recursos mais sólidos da psicogeografia. "A deriva é um modo de comportamento experimental numa sociedade urbana. Além de modo de ação é um meio de conhecimento, especialmente no que se refere à psicogeografia e à teoria do urbanismo unitário. Os outros meios, como a leitura de fotos aéreas e mapas, o estudo da estatística, de gráficos ou de resultados de pesquisas sociológicas, são teóricos e não possuem este lado ativo e direto que pertence à deriva experimental" (p.80).

Com estas e outras propostas, os Situacionistas criaram atividades para combater o que, segundo eles, seria a pior característica do mundo do espetáculo: a alienação advinda de uma participação da sociedade como público espectador do mundo, sociedade como platéia e não como palco.

Este pensar com paixão, pode ser lido de diferentes maneiras neste livro. A primeira é a linear. Como os textos estão organizados por ordem cronológica, e a Apresentação de Berenstein contextualiza a Internacional Situacionista no tempo e espaço, obtém-se um panorama de uma época que não é muito apresentada na história da arquitetura e do urbanismo. É através da apresentação que o leitor poderá entender as relações entre os Situacionistas e o Team X, e também entre outros grupos e intelectuais da época, como Henri Lefevbre.

Outra maneira. Esqueça a Apresentação e concentre-se nos textos situacionistas, absorvendo o máximo dos conceitos apresentados pelos diferentes autores: o desvio, deriva, espetáculo, psicogeografia etc., voltando o pensamento para a produção da crítica feita às cidades nas últimas décadas. Parece que grande parte da crítica contemporânea já estava pronta lá atrás, só que de maneira muito mais radical. Depois disso, volte a apresentação, sem esquecer de ler as notas e se verá que é isso mesmo.

A última possibilidade que apresento é a de fazer deste livro um jogo, e com ele produzir uma deriva própria para cada leitor. Como cada frase contém em si própria uma força propulsora à reflexão e ao conhecimento, abra o livro aleatoriamente e deixe reverberar pelo corpo as palavras lidas. O leitor "sentirá" que existem vários níveis a que estes textos remetem e que, com eles, poderá criar uma situação que lhe permitirá vislumbrar uma crítica à sociedade de consumo, um discurso manifesto apaixonado da vida urbana e, também um espaço de fruição que é mesmo da ordem do artístico, como se cada conceito fosse uma obra de arte mexendo com delicados tecidos sensoriais. É a participação em um encontro entre uma leitura do marxismo e da psicanálise. Depois aconselho a voltar para a apresentação e para uma leitura linear, para melhor compreensão do contexto apresentado.

Enfim, pode-se supor que este tema não tenha nada de acadêmico no que diz respeito aos estudos urbanos e regionais. Entretanto, a revisão da história do urbanismo do ponto de vista de quem o critica em favor de uma vida urbana participante só pode enriquecer a própria história e saber do campo. 